\title{
Is There Abduction in Aristotle? Peirce, Eco, and Some Further Remarks
}

di Giampaolo Proni

Università di Bologna, Dipartimento di Scienze per la Qualità della Vita giampaolo.proni@unibo.it

\begin{abstract}
In several places of the Collected Papers ${ }^{1}$, Peirce states that Abduction, or adoption of a Hypothesis, the form of inference he has discovered and described, could be found in Aristotle, though not fully developed. Umberto Eco (1983), investigates, following Peirce, the presence of abductive elements in Aristotle, and extends Peirce's scope, finding more traces of hypothetical logic. The purpose of this article is to extend and refine the inquiry, trying to answer the question "Did Aristotle know Abductive reasoning?”
\end{abstract}

\section{Key Words}

Abduction, Aristotle, Peirce, Eco, inference

\section{Contents}

Prior Analytics, II, 25, 69a

Abduction in Peirce

The Three Kinds of Inference

Levels of Abduction

Aristotle and Inquiry

Catching the Middle

Conclusions

References

1 See for instance the texts starting at 1.65 (c.1896), 2.730 (1883), 2.776 (1901), 5.144 (1903), and in particular 7.249 (1901), offering the largest discussion on Aristotle's Abduction. The Collected Papers (CP) are commonly cited by the volume number : paragraph number system. I will add the year as reported in the Bibliography of CP. 


\section{Prior Analytics, II, 25, 69a}

In Aristotle, Deduction consists of the inference of a Conclusion from a Major Premiss and a Minor Premiss; it "shows by the middle term that the major extreme applies to the third" (An.Pr. II, 23, 68b, 30-35) ${ }^{1}$. In heuristic terms, we say that we possess the certainty of the Major and the Minor Premisses and we obtain the demonstration of the the Conclusion. Deduction, in its cardinal expression as first figure syllogism, represents the perfect application of the transitive property: "if A is predicated of all B, and B of all C, A must necessarily be predicated of all C" (An.Pr. I, 4, 25b, 35-40). According to Aristotle, all the syllogisms of other kinds can be demonstrated only by reducing them to the first figure.

Beside Deduction, Aristotle recognized as an argument Induction or, strictly speaking, "inductive syllogism" (An.Pr. II, 23, 68b, 15-20).

In Induction we infer the demonstration of the Major Premiss from the other two propositions; it consists "if $\mathrm{B}$ is the middle term of $\mathrm{A}$ and $\mathrm{C}$, in proving by means of $\mathrm{C}$ that A applies to B" (An.Pr. II, 23, 68b, 15-20). Taking Aristotle's example, if A stands for long-lived and B indicates that which has no bile, and $\mathrm{C}$ indicates the long-lived individuals, such as man and horse and mule; then, since we can predicate $\mathrm{AC}$ ("long-lived individuals are man, horse, mule") and BC ("not-having-bile individuals are man, horse, mule"), we can predicate A of B ("long-lived individuals are not-having-bile individuals"), and obtain the rule that longevity and absence of bile are somehow necessarily connected. But, if we reconstruct the argument, we see that the inference "AC, $\mathrm{BC}$, then $\mathrm{AB}$ " does not conform to the scheme of the first figure, therefore is not valid.

Induction becomes valid only through a modification that allows us to reduce it to the first figure. We must perform a conversion of the two terms B and $\mathrm{C}$, that is, we must predicate not-having-bile of all long-lived individuals as well as being long-lived of all not-having-bile individuals ("man, horse, mule, etc. are not-having-bile individuals".)

We are allowed to perform this conversion because, if we enumerate all the long-lived individuals and if we predicate of every one of them the property not-having-bile, there is not a single bile-less individual which is not long-lived; namely $\mathrm{C}$ is the totality of long-lived individuals. Thus we are allowed to perform the conversion from $\mathrm{BC}$ to $\mathrm{CB}$ ("man, horse, mule, etc. are all the not-having-bile individuals"), and so to obtain a first figure syllogism: "AC, $\mathrm{CB}$ then $\mathrm{AB}$ ". The minor term (B) and the middle term (C) swap their place in the Minor Premiss. It is crucial that the universal quantification allow us to convert the terms. That the set of individuals given in $\mathrm{C}$ is the totality of

1 Aristotle's original texts are from 1960, 1962, as well as the translations. The other editions listed in the References have been used as comparisons. For a GreekEnglish good dictionary see http://www.perseus.tufts.edu/hopper/. 
Giampaolo Proni | Is There Abduction in Aristotle?

individuals possessing the character B allows us to turn a series of individual predications into a universal affirmative proposition ("all long-lived individuals are bile-less"). Demonstrative logic in Aristotle is always confined to the deductive form. Experience and intuition play a role, but not in demonstrative processes.

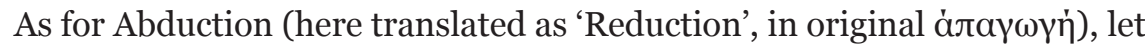
us quote the whole passage considered by Peirce (An.Pr. II, 25, 69a 20-85):

We have Reduction (1) when it is obvious that the first term applies to the middle, but that the middle applies to the last term is not obvious, yet nevertheless is more probable [credible $]^{2}$ or not less probable [credible] than the conclusion; or (2) if there are not many intermediate terms between the last and the middle; for in all such cases the effect is to bring us nearer to knowledge. (1) E.g., let A stand for 'that which can be taught,' B for 'knowledge' and C for 'morality.' Then that knowledge can be taught is evident; but whether virtue is knowledge is not clear. Then if $\mathrm{BC}$ is not less probable [credible] or is more probable [credible] than $\mathrm{AC}$, we have reduction; for we are nearer to knowledge for having introduced an additional term, whereas before we had no knowledge that $\mathrm{AC}$ is true. (2) Or again we have reduction if there are not many intermediate terms between B and C; for in this case too we are brought nearer to knowledge. E.g., suppose that $\mathrm{D}$ is 'to square,' $\mathrm{E}$ 'rectilinear figure' and $\mathrm{F}$ 'circle.' Assuming that between $\mathrm{E}$ and $\mathrm{F}$ there is only one intermediate term-that the circle becomes equal to a rectilinear figure by means of lunules-we should approximate to knowledge.

Aristotle seems to admit two kinds of Abduction. In the first case we have an inference in which $\mathrm{AB}$ ("being teachable can be predicated of knowledge") is evident, but $\mathrm{BC}$ ("knowledge is morality") is not, thus we are not allowed to conclude AC ("being teachable can be predicated of morality"), which would give us a regular Deduction. However, if knowledge and morality are closer than being teachable and morality, we have some approximation to knowledge, though not real knowledge.

The second example concerns the old problem of squaring the circle. To conclude that the circle can be squared we should write the following Deduction:

(1) DE (being squared can be predicated of all rectilinear figures), which is evident;

$\mathrm{EF}$ (rectilinear figure can be predicated of the circle) which is not;

$\mathrm{DF}$ (being squared can be predicated of the circle).

Yet, if we have just a single case of EF (the squaring of the circle by the lunules ${ }^{3}$ ) we are also closer to knowledge.

These two kinds of argument are similar, and Aristotle seems to imply that there are degrees in knowledge, namely, that between possessing or not possessing it there are many intermediate positions.

2 The translation of лıбтó (literally "to be trusted") as "credible" is to be preferred to "probable", as it was by Peirce (see CP 7.249). Probability as we use the term today was totally unknown to ancient Greeks.

3 It was a method introduced by Hippocrates of Chios in the 5 th. cent. BCE. See <https://goo.gl/N6TJ2X $>$ 
Giampaolo Proni | Is There Abduction in Aristotle?

Probably Peirce was impressed by this Aristotelian theory, and thought it had much in common with his own. Actually, in the first writings on inference, we find some similarities between Aristotle's and Peirce's theories. In "Deduction, Induction and Hypothesis" (CP 2.619-644) an article published in 1878, Peirce writes:

Hypothesis is where we find some very curious circumstance, which would be explained by the supposition that it was a case of a certain general rule, and thereupon adopt that supposition. Or, where we find that in certain respects two objects have a strong resemblance, and infer that they resemble one another strongly in other respects.

Here Peirce gives two different definitions of Abduction. The second somehow quantifies Aristotle's concept of 'more credible' introducing 'respects' or 'characters', entities that can be counted (CP 2.632).

Peirce in 1878 sees Induction and Abduction as similar:

The analogy of hypothesis with induction is so strong that some logicians have confounded them. Hypothesis has been called an induction of characters. A number of characters belonging to a certain class are found in a certain object; whence it is inferred that all the characters of that class belong to the object in question. (CP 2.632)

However, he is also aware that the similarity between the two kinds of inference cannot be brought too far:

This certainly involves the same principle as induction; yet in a modified form. In the first place, characters are not susceptible of simple enumeration like objects; in the next place, characters run in categories. (ib.)

Peirce in the following years evolves his approach to logic, in particular during his stay at the Johns Hopkins, from 1879 to 1884 . Yet, in 1883, in "A Theory of Probable Inference", he is still convinced that Abduction (then called Hypothesis) has a quantitative aspect (see in part. 2.706, 707).

Now, before we pass on to a more complete comparison with Aristotle's theory, it might be useful to have a more accurate view of Abduction in Peirce.

\section{Abduction in Peirce}

According to Peirce Abduction is the argument which infers the Minor Premiss from the two other propositions.

Taking the following Deduction:

(2) Rule: All computers (B) are electronic machines (A);

Case: This device (C) is a computer (B);

Result: This device (C) is an electronic machine (A); 
Giampaolo Proni | Is There Abduction in Aristotle?

the corresponding Induction would be:

(3) Case: These devices (C) are computers (B);

Result: These devices (C) are electronic machines (A);

Rule: All computers (B) are electronic machines (A);

and the Abduction would be:

(4) Result: This device (C) is an electronic machine (A);

Rule: All computers (B) are electronic machines (A);

Case: This device (C) is a computer (B).

Let us first analyse the last two arguments from an Aristotelian point of view. The former argument, Induction, comes to the Conclusion by means of the co-presence of two different predications (to be computers and to be electronic machines) in every individual of a set. According to Aristotle, this inference is valid, as we have seen before, only if the individuals considered are the totality of the individuals to whom the first predicate refers, that is to say, if C and B are convertible. It has to be noted that the Conclusion of Induction (and only of Induction) is a Rule.

Now, if we examine Abduction, we see that it draws the Conclusion by means of the co-presence of the same predicate in two different subjects. It is plain that the conclusion does not follow necessarily from the premisses, since the argument cannot allow the conversion of $\mathrm{BA}$ into $\mathrm{AB}$ (it is not necessary that all electronic machines be computers). If it was so the major term could take the place of the middle term and the transitive rule would be valid. To reduce Abduction to the first figure we should perform a conversion not concerning the terms of the Case (which in this inference is the Conclusion) but instead the terms of the Rule (which stands as Minor Premiss). But the conversion of the Rule cannot be performed by simple enumeration, since it is not a predication concerning a certain number of individuals that are all the individuals to whom a predicate refers, but a relation between two general predicates. It is plain that the conversion of the Rule "all the computers are electronic machines" into "all the electronic machines are computers" cannot be obtained by simple enumeration, since we would turn a relation of one-way implication into one of reciprocal implication.

It is evident also that there is a basic difference between the modality of conversion of Induction and that which we should perform to convert an Abduction. In the case of Induction the totality of the individuals to whom the predicate refers is stated in the premiss: the only difference between being long-lived and the long-lived individuals (provided we can list all the individuals of the category) is that the latter is an exhaustive enumeration and the former a universal term. But the extension of the two expressions is the same. Thus, in performing the conversion, we do not introduce any new information. But in the case of Abduction our conversion would be absolutely arbitrary. The Rule as it stands can be converted only in "some electronic machines are computers", but we are logically not allowed to state that, in the mode of necessity, the device we talk about is one of them. 
Giampaolo Proni | Is There Abduction in Aristotle?

\section{The Three Kinds of Inference}

Peirce, in fact, has a completely different theory of logical modes ${ }^{4}$. He maintained that in the three kinds of inference we find three different kinds of relatives (subject-predicate connectives). Furthermore, the three modes of inference are, in Peirce, the expression of the three phaneroscopic (phenomenological) categories, that is, not of three formal modes, but of three modes of appearance, which give rise to three different criteria of validity. According to Peirce, Induction is valid even if the individuals considered are not the totality of the set. In such an inference the conclusion must be stated not in the mode of necessity, but in the mode of actuality, of experience. In the conclusion of Deduction and Induction the copula is does not have the same meaning. In the former the meaning is conventional, symbolic, formal: "is, according to certain rules"; in the latter is factual, perceptive: "according to experience as far as now." It is quite the same in Abduction, but the mode is that of possibility: "it possibly is." Such possibility, as a formal modality, is of little value, but its importance is paramount because it is the most powerful argument in the heuristic process.

Induction comes in when experience has already received a certain pattern, and it quantifies and generalises it. Abduction, in its turn, supplies the patterns to this process. Abduction, in Peirce, is then a valid argument in the mode of pragmatic possibility. The three inferences, taken together, make the logic backbone of scientific inquiry, and must be applied in the sequence Abduction-Deduction-Induction. Moreover, the three-step process must start with experimental data and end by testing its conclusions ${ }^{5}$.

However, the presence of the phaneroscopic categories in inference was not evident to Peirce until the beginning of the 2oth century, and because of this unclearness he continuously tries to describe the three inferences in the same formal way, running the risk of loosing the original nucleus of his approach (as he sometimes actually does). Searching for strictly argumentative classifications Peirce forgets the 'categorial' differences of the three logical principles. Peirce himself recognized it, and confessed (CP 2.102 1902) that he had given the syllogistic forms too much importance, especially in Induction and Abduction:

I was too much taken up in considering syllogistic forms and the doctrine of logical extension and comprehension, both of which I made more fundamental than they really are. As long as I held that opinion, my conceptions of Abduction necessarily confused two different kinds of reasoning. When, after repeated attempts, I finally succeeded in clearing the matter up, the fact shone out that probability proper had nothing to do with the validity of Abduction...

4 Peirce followed and contributed to found the Logic of Relatives, which basically diverges from the Aristotelian theory in that besides the relation of 'being equal to' other types of connection between terms are taken into account.

5 See in particular "On the Logic of Drawing History from Ancient Documents Especially from Testimonies” 7.164-255 (1901). 
Giampaolo Proni | Is There Abduction in Aristotle?

In the light of this approach, when Peirce, in 7.164-255 (1901), tried to demonstrate that Aristotle was actually founding Abduction as an hypothetical argument in chapter 25 of book II of Prior Analytics, he was forced to suppose large corruptions in the original text. Peirce shows a keen heuristic desi-

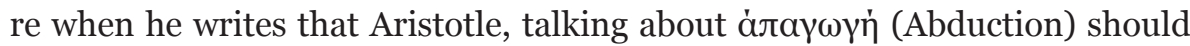
have written "which conclusion (of the argument) we discover to be a fact" (CP 7.249). The excessive heuristic desire betrayed Peirce: in Aristotle, propositions forming syllogisms are never facts, in the sense of tested experience ${ }^{6}$. Thus we should conclude that in Aristotle we cannot find any theory of Abduction, at least in the form we know from Peirce.

Nevertheless, following Eco's suggestion, it is possible to look for Abduction elsewhere in the Aristotelian works (Eco 1983: 198ff).

In order to have a more exhaustive presentation of the issue, though, we must first of all introduce another point, namely, the types of Abduction and its role in scientific inquiry.

\section{Levels of Abduction}

In Peirce there is no reference to different types of Abduction, since in $\mathrm{Ab}$ duction the category of Firstness is prominent, and Firstness does not divide into types. Nonetheless, studies by Bonfantini and Proni, Eco and Thagard showed that a typology of Abduction is in some way implicit in his work. Thagard (1978) was the first to expose that the Abductive inference has two possible forms, namely, that we may infer the Case, but we may also infer the Rule. Here are the examples:

\section{(5) Inference of the Case}

Result: This device (C) is an electronic machine (A);

Rule: All computers (B) are electronic machines (A);

Case: This device (C) is a computer (B).

(6) Inference of the Rule

Result: This device (C) is an electronic machine (A);

Case: This device (C) is a computer (B).

Rule: All computers (B) are electronic machines (A).

Unfortunately, it seems to me that Thagard mixes up Abduction and Induction (1978: 167). (6) is only an Induction based on a single individual. If the device was the only computer in the world, then we could reverse the Case (from CB to BC) and have an Aristotelian valid Induction. As Eco writes (1983: 203), if there is another kind of Abduction it is not the inference of the Rule from Case and Result, but the inference of Rule and Case together from just one proposition.

Starting with the Result;

(7) Result: This device (C) is an electronic machine (A);

6 See the first chapters of De Interpret., An.Pr., An.Post. 
Giampaolo Proni | Is There Abduction in Aristotle?

we infer both the Rule:

Rule: All computers (B) are electronic machines (A);

and the Case:

Case: This device (C) is a computer (B).

Eco seizes the opportunity, at this point, to expand on how important is the choice of the middle term, but we must stress that, if we accept such a model of reasoning we abandon the field of formal logic, since inference, by definition, starts from two given propositions and proceeds without introducing any new information. However, if we look at reasoning as it is performed in the practice of inquiry in science and detection, the inference from a fact to its explanation begins with the equivalent of a proposition and then looks for for Case and Rule. Suppose we find an electronic machine of a kind we are not able to ascertain. This is our explanandum (fact to be explained), or surprising fact.

The difference is where the Rule comes from: if we have it at hand, then the conclusion, though only possible, is given. If we don't, we must either choose it from a set of possible rules or make a new one. It is on this dimension that the typology by Bonfantini and Proni (1983: 133-134) is set. Three degrees of innovation are marked on an axis that we suppose to be continuous. At one end we have an automatic springing up of the Rule, or mediation law, as it happens - according to Peirce - in perceptual judgements. In the second case we must look for the Rule among a set of possible explanations, select it "in the available Encyclopedia" (ib.). In the third case, the most creative one, the Rule has to be invented, created ex novo. This is the case with scientific discoveries and innovative solutions in every field of knowledge and technology.

In the logic of inquiry, the inference runs this way:

(8) Result: We see an electronic machine we cannot recognize, that is, a surprising fact, something we are not able to explain;

Rule: We know that "all computers are electronic machines", thus, though a lot of electronic devices are not computers, if this one was a computer, then we would be able to explain it, and we would know what to look for to verify if we are right or wrong;

Case: We adopt the hypothesis that this device is a computer, so we can try some experiments to test it. For instance, we look for a way to turn it on, for an input and an output unit and so on.

It is more complicated when there is no good Rule, or mediation law, neither automatically given nor stored in the available knowledge. This was the case with Kepler's inquiry on the orbit of Mars, that Peirce defined as "the greatest piece of Retroductive ${ }^{7}$ reasoning ever performed" (CP 1.74 c.1896).

Here is how Peirce presents Kepler's discovery:

7 'Retroduction' is in Peirce another term for Abduction. 
Giampaolo Proni | Is There Abduction in Aristotle?

... at a certain stage of Kepler's eternal exemplar of scientific reasoning, he found that the observed longitudes of Mars, which he had long tried in vain to get fitted with an orbit, were (within the possible limits of error of the observations) such as they would be if Mars moved in an ellipse. The facts were thus, in so far, a likeness of those of motion in an elliptic orbit. Kepler did not conclude from this that the orbit really was an ellipse; but it did incline him to that idea so much as to decide him to undertake to ascertain whether virtual predictions about the latitudes and parallaxes based on this hypothesis would be verified or not. This probational adoption of the hypothesis was an Abduction. (CP 2.96 c.1902)

In short, Kepler had a series of positions through which the planet passed in the sky:

(9) Result: Mars transits through the points $x_{1}, x_{2}, \ldots x_{n}$,

but he could find no regular curve, expressed as an equation, on which all the points could lie. A circumference was excluded, and an oval as well. He tried with a complicated combination of epicycle and deferent (a smaller rotation having its centre on a larger circle which in its turn rotates) until in a flash he realised that an ellipse could provide the same path with a simpler equation (Proni 1983).

Kepler invented a Rule that said:

Rule: If the orbit is elliptical, then it will transit through the points $x_{1}, x_{2}, \ldots x_{n}$.

However, he could not exclude that a different curve might fit with those positions, that is to say, it was not true that only an ellipse could pass through the points he was working with. Thus the conclusion:

Case: Mars follows an elliptic orbit.

was not sure, though it was a very solid explanation, so much as to be, today, a law of astronomy.

In short, the inventive step of Abduction is not in the conclusion, but in the choice of the Rule, or mediation law, or middle term.

The two propositions thus produced in the 'incomplete' type of Abduction constitute an explanans of the first proposition, which indeed can be put as a conclusion of the two taken as premisses, thus producing a Deduction, that represents the Law as already established and applied to a case.

(10) Mars follows an elliptic orbit;

An elliptic orbit will transit on the points $\mathrm{x}, \mathrm{x}_{1}, \mathrm{x}_{2}, \ldots \mathrm{x}_{\mathrm{n}}$;

Mars transits through the points $\mathrm{x}, \mathrm{x}_{1}, \mathrm{x}_{2}, \ldots \mathrm{x}_{\mathrm{n}}$.

Incomplete Abduction actually finds the middle term. This way we have two types of Abduction, or better two degrees of completeness, corresponding to two different approaches to inference.

The first is the logic of inquiry, the quest for the Rule, or middle term, which allows us to use the inference as an explanation. The second considers 
Giampaolo Proni | Is There Abduction in Aristotle?

the complete argument (indeed, given the premisses, we come mechanically to the conclusion), and its heuristic power depends on how strong (or better how weak) is the possibility that the conclusion be true. The weaker the possibility, the stronger the innovative leap thus produced, of course pending the experimental test of the conclusion.

However, these two levels are logically similar, since in both cases we look for a middle term between two terms. In the first-degree, or incomplete, Abduction, we are concerned with finding, roughly speaking, a link allowing us to establish a connection. The way we find the link, i.e. the Rule, opens to another typology.

In the second degree we are concerned with specifying the logical strength of the connection, in a range that goes from vague possibility to a relationship that allows us to perform the conversion of the Rule, transforming the Abduction into a Deduction.

\section{Aristotle and Inquiry}

The brilliant works of M. F. Burnyeat (1982, 1994, 1996) have demonstrated with great clearness and an extraordinary insight in the mentality of the author "that Aristotle does think that syllogistic is a universal test of formal or deductive validity, but he does not think that formal or deductive validity is the only test of whether an argument is intellectually respectable or has a justifiable claim on rational minds" (1982: 201). In particular, Aristotle stresses how more relaxed kinds of reasoning find their proper application in rhetoric, that is, the discourse in court or in the assembly. Burnyeat is correct in defining as pioneering the discovery that a formally invalid argument "can make a rightful claim on rational minds" (1982: 203), and vast areas of the Aristotelian works have been enlightened by his approach. Nonetheless, Aristotle cannot go further than that: he is unable to explain how an invalid arguments works, and how we can rank those arguments from good to poor (ib.). Lacking the connection of logical reasoning to experimental observation and a modern theory of probability, in short, the model of scientific inquiry, he could see the use of non-deductive reasoning only as a way to persuade an audience or win a discussion, but not as an instrument for the advancement of knowledge. Thus, if we limit ourselves to the logic of necessary reasoning (as Aristotle did), we can use Abduction only as an emergency tool, weaker than Induction, in its turn weaker that Deduction, to be adopted when we have no other choice. However, we do not use reasoning only to study the different ways to draw a conclusion, but also as an instrument to know and explore. Aristotle himself seems to realise the importance of finding an explanation:

Quick wit is a faculty of hitting upon the middle term instantaneously ${ }^{8}$. It would be exemplified by a man who saw that the moon has her bright side always turned towards

8 NdA. The Greek text has the word áyкivora, which means "ready wit, sagacity,

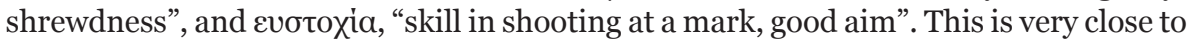
what Peirce said about the "power of guessing right", like he tells relating the episode of the stolen watch in which he acted as a detective (see Peirce, 1929). 
Giampaolo Proni | Is There Abduction in Aristotle?

the sun, and quickly grasped the cause of this, namely that she borrows her light from him, or observed somebody in conversation with as man of wealth and divined that he was borrowing money [...]. In all these instances he has seen the major and minor terms and then grasped the causes, the middle terms. (An.Post. I, 34, 89b, 10-15)

These examples fit perfectly Peirce's model of Abduction as explanation, or first degree Abduction. In both cases a general law must be found. In the former, the law might be expressed as "if a planet is lighted from the sun, then the bright side is turned towards the sun", in the latter as "if a man wants to borrow money, then he must talk to a rich man". We must note that neither of the rules can be reversed, namely, it is not true that if a planet is turned towards the sun it is lighted by it ${ }^{9}$, and it is not true that if somebody talks to a rich man it means he wants to borrow from him. Aristotle, then, adds:

Let $A$ represent 'bright side turned sunward', $B$ 'lighted from the sun', $C$ the moon. Then $B$, 'lighted from the sun', is predicable of $C$, the moon, and $A$, 'having her bright side towards the source of her light', is predicable of $B$. So $A$ is predicable of $C$ through B. (An.Post. I, 34, 89b, 16-20)

If we write this in a clearer form we obtain a Deduction:

(11) The moon (C) [is] 'lighted from the sun' (B);

[what is] 'lighted from the sun' (B) [has its] 'bright side turned sunward' (A);

the moon (C) [has its] 'bright side turned sunward' (A).

As I described above, this inference corresponds to the situation of knowledge after the experimental test has proved the validity of Abduction: a settled rule. Aristotle is aware that the faculty of "quick wit" is somehow logical, and accepts non-deductive reasoning as a useful tool in specific fields, but, admitting only the necessary mode, he cannot see in Abduction any power to come to the truth.

The Abduction capable of finding an explanation of the surprising fact $\mathrm{A}$ ('the moon has her bright side always turned towards the sun') is the following:

(12) The moon (C) [is] 'bright side turned sunward' (A);

'lighted from the sun' (B ) [is]'bright side turned sunward' (A);

the moon [(C) [is] 'lighted from the sun' (B ).

The second example is analogous: A will be an acquaintance of ours, and C will be 'talking with a rich man'. The proposition $\mathrm{AC}$ will be the starting point of inquiry. We want to explain this fact AC. Now, it is the datum that we introduce as the second, namely B, borrowing from him, that resolves our inquiry.

In either case we introduce a rule; we propose a middle term. How does this happen?

9 At Aristotle's times the difference between planets and stars was not clear. 
Giampaolo Proni | Is There Abduction in Aristotle?

\section{Catching the Middle}

As we have seen, both Aristotle and Peirce agree that, when an explanation is required "The middle term is the triggering device of the whole process" (Eco 1983: 203).

Now the question is: is there a logical or at least rational way for "hitting upon the middle term", or is it just a question of intuition, or of chance?

According to Aristotle, the inquiry can take four directions, in order to ascertain (1) that, (2) why, (3) whether the thing exists, and (4) what it is. Once we have ascertained that a thing is something, or that it exists, we can investigate why or what that thing is, and this means investigating "whether the thing has a middle term or not", that is to say, a cause (An.Post., II, 2, 89b, and 23ff-90a 1-5).

However "In all these cases it is obvious that the question of essence and the question of cause are identical." (An.Post. II, 2, 90a, 14). So, the why and the what, and the cause or middle term and the essence are the same. To say what a thing is means to give its definition: "the definition is [...] belonging to its essence." (An.Post. II, 4, 91a, 14). And then Aristotle goes on to define definition.

First he specifies that a definition is not a demonstration, since the latter "proves that an attribute is, or is not, predicated of a subject" (An.Post. II, 3, 91a, 1), while "To reveal the essence of a thing is not the same as to prove a proposition about it" (An.Post, II, 3, 9ob, 35). Namely, to say what a thing is, is very different from saying that a thing is something (subject-predicate connection). This is quite important: if definitions were the same as demonstrations, there would be no room for inquiry, but from every term all the possible middle terms would automatically spring up. It is not so, and the demonstration of a definition cannot exist. However, there exists a dialectic syllogism, that can deduce essence (An.Post. II, 8, 93a, 15). Such a syllogism, starting with the knowledge that a thing is something (and then, implicitly, that it exists), states that there is a reason, a speech ( $\lambda$ óyos) of this 'something'. Definitions act as immediate, unquestionable premisses: "when we have discovered the answer we know simultaneously both the fact and the reason for it-if the premisses are immediate" (An.Post, II, 8, 93a, 35). Let us see Aristotle's example: "C is 'moon,' A 'eclipse,' B 'the inability of the moon at its full to cast a shadow, there being nothing visible in the way.' Then if B, 'inability to cast a shadow although there is nothing in the way,' applies to $\mathrm{C}$, and $\mathrm{A}$, 'being eclipsed,' to B, it is obvious that there is an eclipse, but it is not yet obvious why" (An.Post. II, 8, 93a, 35-93b 1).

In a propositional approach, indeed, it corresponds to the search for an antecedent, the consequent being given, while in an argumentative approach it corresponds to the search for a middle term.

Now, this procedure is similar enough to Peirce's Abduction to confirm what was stated by Eco when he pointed out that Abduction in Aristotle was less evident in Prior Analytics, where Peirce thought to have found it, than in Posterior Analytics, where definition is treated (1983: 198ff) ${ }^{10}$.

10 Burnyat's work, once more, has shown that something very similar to Abduction 
Giampaolo Proni | Is There Abduction in Aristotle?

\section{Conclusions}

We have seen that Peirce was wrong when he identified Abduction - seen

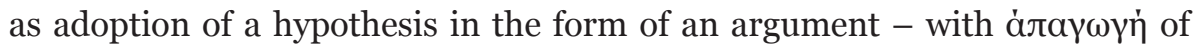
Chapter 25 of the First book of Prior Analytics, because Aristotle does not admit different inferential principles, but just weaker or invalid deductive arguments. However, by elaborating Peirce's theory until we find as the nucleus of the abductive inference the choice of the middle term, we have seen that this matter is actually treated in Aristotle's theory of definition. But, according to Aristotle, definitions are indemonstrable and so they relate on the one hand to the voús (direct intuition) and on the other to dialectic, the discussion based upon dialogue of arguments and counter-arguments. Aristotle's difficulty to acknowledge the role of Abduction in the search for truth is not a consequence of an incapacity to see how this kind of reasoning can be useful, but of a background that denied validity to non-sillogistic reasoning. Peirce's solution, and the whole change of paradigm produced by scientific method, was possible because, in inquiry, valid reasoning became less important than the capacity to produce explanations by means of the heuristic power of hypotheses and the final role of experimental testing.

Thus, the answer to the question whether Aristotle knew Abduction is not sharp. From the mere logical point of view he acknowledged several forms of uncertain reasoning. In Aristotle we find not only the syllogistic form of Abduction, but also that of incomplete abduction, very similar to the theory Peirce himself evolved, based on his theory of categories. Yet he did not see it as capable of producing knowledge in the sense of solid scientific conclusions. Also enthymeme is to be considered, another kind of argument where traces of reasoning from effect to cause can be found (see Burnyeat 1994 and 1996)

The great paradigms of culture and thought seem to be like invisible blinkers, that allow even a brilliant mind to see only the path before its eyes. To less brilliant minds, as that of the author, even a clear vision of what is just beyond the nose is sometimes foggy.

Like in a labyrinth of mirrors, Peirce thought he had found Abduction in Aristotle, where it was not; furthermore, what he was looking for was not the theory as he eventually shaped it; and that final shape, in its turn, was foreshadowed by Aristotle in a place Peirce had not considered.

\section{References}

Aristotle

1928 The Works of Aristotle, Vol. I, translated by W. D. Ross, Oxford, Oxford University Press (1937, 1950: London, Lowe \& Bryndone, printers).

1960 Posterior Analytics, by Hugh Tredennick, in Posterior Analytics, Topica, London, William Heinemann and Cambridge Mass., Harvard University Press.

can be found also in the Rhetoric (Burnyeat 1994, 1996) and at least in one passage from Sophistical Refutations (167b1-12) (1982 n24). 
Giampaolo Proni | Is There Abduction in Aristotle?

1962 Prior Analytics, by Hugh Tredennick, in The Categories, On Interpretation, Prior Analytics, Loeb Classic Library, London, William Heinemann and Cambridge Mass., Harvard University Press.

1973 Opere. Vol 1., traduzione di Marcello Gigante e Giorgio Colli, Bari, Laterza.

Bonfantini, M.A. and Proni, G.

1983 “To Guess or Not to Guess", in Eco and Sebeok 1983.

Burnyeat, M. F

1982 "The origines of non-deductive inference", in J. Barnes, ed., Science and Speculation. Studies in Hellenistic theory and practice, Cambridge, Cambridge University Press; Paris, Editions de la Maison des sciences de l'homme.

1994 "Enthimeme: Aristotle on the logic of Persuasion", in D. J. Furley and A. Nehamas (eds.), Aristotles Rhetoric: philosophical essays, Princeton, Princeton university press.

1996 "Enthymeme: Aristotle on the Rationality of Rhetoric", in A. Oksenberg Rorty, ed., Essays on Aristotle's Rhetoric, Berkeley, University of California Press.

Eco, U. and Sebeok, T. A. (eds.)

1983 Dupin, Holmes, Peirce. The Sign of Three, Bloomington, Indiana University Press.

Eco, Umberto

1983 “Horns, Hooves, Insteps. Some Hypotheses on Three Kinds of Abduction”, in Eco and Sebeok 1983.

Fann, K.T.

1970 Peirce's Theory of Abduction, Martinus Nijhoff, The Hague.

Peirce, Charles Sanders

1931-1958 Collected Papers, Cambridge (Mass.), Harvard University Press.

1929 "Guessing", The Hound and Horn 2 (April-June 1929), parts in 7.36-48 (c.1907), now available at http://www.nepistemology.com/docs/hound-andhorn.pdf

Proni, G.

1983 “L'abduzione di Keplero", in VS 34, Bompiani, Milano.

Thagard, Paul R.

1978 "Semiotics and Hypothetic Inference", Versus 19/20, Bompiani, Milano. 